\title{
KEBIJAKAN WAWASAN KEBANGSAAN DAN PENANGANAN \\ KONFLIK SOSIAL DALAM PRESPEKTIF COLLABORATIVE GOVERNANCE DI KABUPATEN PANDEGLANG
}

\author{
${ }^{1}$ Rusdjiman Soemaatmadja, ${ }^{2}$ Tjahja Supriatna, ${ }^{3}$ Hyronimus Rowa, ${ }^{4}$ Kusworo \\ ${ }^{1,2,3,4}$ Institut Pemerintahan Dalam Negeri (IPDN) \\ Email: jimans1957@gmail.com
}

\begin{abstract}
Abstrak
Memperhatikan perkembangan kehidupan berbangsa dan bernegara yang sedang mengalami gejolak dengan adanya konflik yang berlatarbelakang SARA, separatisme, radikalisme dan terorisme yang terjadi jika ditelusuri memiliki hubungan dengan Kabupaten Pandeglang terkait dengan penduduknya. Hal ini juga ditunjukan dengan tingginya data konflik yang terjadi di Kabupaten Pandeglang di antara Kabupaten/Kota di Provinsi Banten. Penelitian ini menggunakan pendekatan kualitatif, sehingga dalam memaknai kondisi para aktor lebih dikembangkan dengan alat analaisis triangulasi. Hasil penelitian ini menemukan bahwa implementasi kebijakan wawasan kebangsaan masih belum berlangsung baik secara kolaboratif, sehingga banyak menimbulkan permasalahan sosial di tengah masyarakat yang diakibatkan oleh faftor sumber daya manusia, dan anggaran.
\end{abstract}

Kata Kunci: Implementasi Kebijakan, Wawasan Kebangsaan, Collaborative Governance.

\section{Abstract}

Paying attention to the development of the life of the nation and state which is experiencing turmoil with the existence of conflicts with a racial background, separatism, radicalism and terrorism which occur if traced have a relationship with Pandeglang Regency related to its population. This is also shown by the high data on conflicts that occurred in Pandeglang Regency among Regencies / Cities in Banten Province. This research uses a qualitative approach, so that in interpreting the conditions of the actors, it is more developed with a triangulation analysis tool. The results of this study found that the implementation of the national insight policy is still not going well collaboratively, causing many social problems in society caused by human resources and budget factors.

Keywords: Policy Implementation, National Insight, Collaborative Governance.

\section{A. PENDAHULUAN}

Pada hakikatnya Indonesia merupakan suatu komunitas besar yang terbentuk atas dasar pengalaman bersama yang mempersatukan bebagai keanekaan etnik, budaya, ras dan agama yang mendiami kepulauan dalam kawasan nusantara. Berdasarkan pandangan historis negara Indonesia sekarang adalah keberlanjutan kesatuan administratif bekas jajahan Belanda. Ketika kita memandang dari sudut pandang histori kebangsaan maka jawaban diatas terlalu kecil maknanya (Stroomberg, 2018). Bangsa Indonesia telah terbentuk jauh sebelum 
adanya Negara Kesatuan Republik Indonesia yakni 17 tahun sebelumnya pada saat sumpah Pemuda (Foulcher, 2000)

Setelah bangsa Indonesia meraih kemerdekaan dengan semboyan Bhineka Tunggal Ika dibawah kepemimpinan Presiden Soekarno telah meletakkan dasar persatuan bangsa dengan mengedepankan nation building dan character building, sekalipun dalam perjalanannya mengalami pasang surut dengan berbagai ancaman, gangguan, hambatan dan tantangan telah menghantarkan bangsa Indonesia sempat berjaya di dunia internasional. Tidak dapat dipungkiri bahwa semangat kebangsaan Indonesia yang mulai tumbuh pada saat perjuangan melawan Belandan dan Jepang terus menjadi motor penggerak sehingga dapat mewujudkan kemerdekaan yang dirasakan sekarang, untuk membingkai rasa kebangsaaan itulah maka Soekarno menuangkan semangat kebangsaan dalam dasar filosofi hidup bangsa Indonesia yakni Pancasila yang disepakati bersama oleh Founding Fathers dan dituangkan dalam Konstitusi Negara.

Makna filosofi yang terkadung dalam Pancasila sebagai lima nilai kessusilaan bangsa Indonesia sebenarnya telah tertanam dalam perilaku kehidupan rakyat Indonesia selama berabad-abad, Soekarno hanya menjadi "perumus" dari intisari nilai-nilai kehidupan berbangsa rakyat Indonesia (Kansil \& Kansil, 2011). Pancasila dan UUD 1945 yang menjadi pilar pembangunan kebangsaan Indonesia menjadi penerus semangat kebangsaan bagi warganegara dalam membangun kebersamaan dalam mewujudkan cita-cita yang telah disepakati bersama. Pancasila sebagai ideologi, kepribadian dan pandangan hidup bangsa Indonesia, sering ditafsirkan secara tidak beraturan (Poespowardojo, 1989) sehingga seakan sebagai sinonim dan menjadi kabur bahkan tidak menunukan arti sesungguhnya.

Pemahaman akan keberadaan kita dalam lingkup Negara Kesatuan Republik Indonesia merupakan intisari dari pandangan wawasan kebangsaan. Nilai-nilai wawasan kebangsaan memiliki peran sentral dalam menjaga sejarah kebangsaan Indonesia dan menjadi pendorng aktualisasi nilai-nilai Pancasila serta menjadi peredam perkembangan egoism kesukuan dan kedaerahan dalam membangun bangsa Indonesia. Disintegrasi bangsa, semua kegagalan yang dialami oleh bangsa ini sebenarnya merupakan gejala yang muncul dari kekeliruan dan kekurangpahaman terhadap pentingnya nilai-nilai Pancasila dalam kehidupan bersama, padahal Sadar atau tidak Pancasila memiliki fungsi integratif yang selalu menjami kesatuan Negara Indonesia yang pluralistik.

Wawasan kebangsaan yang sering dibicarakan memiliki erat kaitannya dengan Pancasila sebagai ideologi, karena Pancasila bentuk dari kristalisasi nilai-nilai wawasan kebangsaan yang sesungguhnya, disamping itu juga nilai-nilai yang terkandung dalam 
pancasila merupakan bagian dari nilai-nilai yang menjadi pedoman kehidupan bangsa Indonesia, sebab dapat mempersathukan keanekaan yang dimiliki Indonesia. Wawasan kebangsaan yang mengkristal dalam filosofi hidup bangsa Indonesia yakni Pancasila, telah diamanatkan dan menjadi bingkai kebijakan nasional dalam RPJPN (Rencana Pembangunan Jangka Panjang Nasional) 2005-2025 yang salah satunya mengamanatkan: menciptakan masyarakat yang memiliki moral baik, memiliki akhlak mulia, mengenali budaya, memiliki etika ketimuran dan beradab sesuai falsafah Pancasila (Nasional, 2005).

Meskipun secara konseptual dan dan struktur bangsa Indonesia telah memiliki nilai, akan tetapi problematika yang dihadapi selalu ada pada proses dan Implementasi Wawasan Kebangsaan baik sebagai suatu Kebijakan maupun sebagai nilai-nilai yang hidup dan berkembang dalam masyarakat, hal ini bisa dijelaskan dengan masih adanya sikap separatisme dan radikalisme yang hidup dan berkembang juga dalam masyarakat (Naisbit, 1994).

Gambaran wawasan kebangsaan yang telah di transformasikan kedalam kebijakan Nasional yakni Undang-Undang nomor 17 tahun 2004 tentang Rencana Pembangunan Jangka Panjang Nasional 2005-2015, penjabaran lanjut dalam kebijakan tersebut yakni penanaman nilai-nilai kebangsaan melalui pendidikan bagi masyarakat secara berkesinambungan yang berorientasi pada konsep Confucius dan mel sibermen (Infopublik, 2016). Sebagai sebuah kebijakan wawasan kebangsaan merupakan bagian yang tidak terpisahkan dari kehidupan bernegara sehingga pemerintah sebagai Policy Maker harus selalu melakukan kegiatankegiatan evaluasi terhadap penanaman nilai-nilai kebangsaan, sehingga kebijakan yang lahir dapat menjadi perekat perbedaan bangsa melalui kesadaran akan nilai-nilai kebangsaan. Kebijakan wawasan kebangsaan selain sebagai sebuah produk pemerintah dan nilai-nilai dari kehidupan bangsa juga merupakan hasil dari proses politik bangsa Indonesia sebagai upaya menjaga keutuhan Negara Republik Indonesia, dan menghindari Negara dari perpecahan dalam masyarakat (Wasistiono, 2015).

Banten tidak luput dari kejadian konflik sosial yang bisa saja mengganggu ketertiban umum dan proses penyelenggaraan pemerintahan daerah. Data menggambarkan bahwa jumlah konflik pada tahun 2015 yang terjadi pada kelompok SARA dengan jumlah total 10 kejadian dan permasalahan sumber daya alam yang berjumlah 11 kasus. Terutama Kabupaten Pandeglang yang dari hasil rekapitulasi memiliki jumlah konflik terbanyak pada tahun 2011 sebanyak: 11 kasus. Tingginya konflik yang terjadi di pandegelang sudah dikategorikan level rawan sebab pada 7 kecamatan dan 24 desa menjadi lokasi konflik yang berlatarbelakangkan Lahan yang baik memakan korban maupun mengalami kerugian material. 
Data diatas menggambarkan konflik bahwa kebijakan pemerintah daerah belum mampu mengelolah konflik dengan baik. Aktualisasi nilai-nilai kebangsaan bukan hanya diharapkan menjadi dasar kehidupan bermasyarakat, namun juga menjadi dasar pelaksanaan tugas dan fungsi dalam penyelenggaraan pemerintahan, hal ini yang masih belum menjadi perhatian pemerintah daerah pandeglang. Hal tersebut terbukti masih tingginya jumlah pnduduk pandeglang yang menjadi korban doktrinasi dari gerakan radikalisme. Dorongan yang mendesak penduduk pandeglang secara mudah mengikuti doktrin terorisme merupakan dorongan ekonomi yang masih rendah. Cita-cita luhur pemerintahan hadir untuk mensejahterahkan masyarakatnya belum terwujud di kabupaten Pandeglang.

Berdasarkan uraian latar belakang tersebut, penulis tertarik untuk meneliti dan mengevaluasi secara lebih mendalam dan menyeluruh dalam menangani konflik sosial di Kabupaten Pandegelang Provinsi Banten melalui implementasi kebijakan wawasan kebangsaan dalam perspektif Collaborative Governance.

\section{B. METODE}

Penelitian ini menggunakan pendekatan Kualitatif dengan fokus pada masalah Implementasi Kebijakan Wawasan Kebangsaan dalam menangani konflik sosial, pendekata kualitatif dipilih sebab peneliti ingin mendalami pemahaman semua pihak terkait dengan wawasan kebangsaan secara individual. Menurut Effendy (2010), penelitian kualitatif adalah penelitian yang menjelaskan dan menganalisis perilaku manusia secara individual dan kelompok, prinsip atau kepercayaan, pemahaman atau pemikiran, dan persepsi atau anggapan. Sedangkan menurut Sugiyono (2010) metode penelitian kualitatif dapat diartikan sebagai metode penelitian yang berlandaskan pada filsafat postpositivisme/enterpretif, digunakan untuk meneliti pada kondisi objek yang alamiah, (sebagai lawannya adalah eksperimen) dimana peneliti sebagai instrument kunci, teknik pengumpulan data dilakukan secara trianggulasi (gabungan), analisis data bersifat induktif/kualitatif, dan hasil penelitian kualitatif lebih menekankan makna dari pada generalisasi.

\section{HASIL DAN PEMBAHASAN}

Sejak dasawarsa kedua era reformasi kita telah dikejutkan dengan kenyataan bahwa telah mengendornya semangat kebangsaan dan meningkatnya semangat golongan, disamping itu UUD 1945 sebagai formula konstitusional yang mewadahi semangat kebangsaan dalam kehidupan bernegara tidak lagi menjadi rujukan dalam kehidupan bernegara, bahkan jarang sekali disebutkan dalam perbincangan politik dewasa ini (Nugroho, 2018). 
Gambaran perubahan yang terjadi dalam kaitannya dengan tantangan kebangsaan tersebut jika tidak dicegah dan ditanagani secara baik, bangsa yang bermasyarakat majemuk ini dapat pecah berkeping-keping menjadi satuaan-satuan politik atau satuan-satuan kelompok kepentingan paling kecil yang amat lemahdan saling berkonflik satu dengan yang lain. Untuk itu Kementerian Dalam Negeri pada Tahun 2012 menerbitkan peraturan Menteri Dalam Negeri Nomor 71 Tahun 2012 Tentang Pedoman Pendidikan Wawasan Kebangsaan. Terbitnya Peraturan tersebut menjadi pedoman teknis yang diamanatkan pada UndangUndang Nomor 32 tahun 2009 yang telah diRevisi dengan Undang-Unbdang Nomor 23 tahun 2014 Tentang Pemerintahan Daerah.

Kabupaten Pandeglang telah berusaha mengembangkan kebijakan wawasan kebangsaan yang diimplementasikan lewat pusat pendidikan wawasan kebangsaan yang menjadi wahana diseminasi penanaman nilai-nilai wawasan kebangsaan berdasarkan Peraturan Bupati Nomor 50 tahun 2015 yang diaplikasikan melalui Keputusan Bupati nomor 420/Kep. 107-Huk/2018 tentang Pembentukan Pengurus Pusat Pendidikan Wawasan Kebangsaan Kabupaten Pandeglang Periode 2018-2021. Berdasarkan keputusan tersebut dibentuk pusat pendidikan wawasan kebangsaan yang menghubungkan beberapa pemangku kepentingan yang menjalankan perannya masing masing dalam penanaman nilai wawasan kebangsaan pada penduduk Kabupaten Pandeglang yang berjumlah 1.200.512 orang; dari jumlah penduduk Kabupaten Pandeglang tersebut yang memeluk Agama Islam sebanyak 1.199.311 orang $(99,9 \%)$ kebanyakan warga NU (Nahdiyin) dan sebagian kecil adalah orangorang Muhammadiyah.

Gambaran kondisi tersebut di atas, memposisikan peranan pemangku kepentingan dalam penanganan konflik yang ditunjukan oleh tokoh agama yang ditunjukan oleh NU dan Muhammadiyah sangat penting. Selama ini antara NU dan Muhammadiyah tidak terjadi selisih paham apalagi terjadi bentrok fisik karena keduanya tetap menjalankan syariat Islam. Kepada aliran Ahmadiyah semua umat Islam baik itu NU dan Muhammadiyah menentang adanya aliran Ahmadiyah tersebut karena tata cara beribadahnya agak menyimpang dari Syariat Islam, sehingga jemaat Ahmadiyah dianggap telah keluar dari ajaran Islam yang sebenarnya. MUI (Majelis Ulama Indonesia) pada tahun 1980 dan tahun 2005 mengeluarkan Fatwa terhadap Ahmadiyah bahwa Ahmadiyah merupakan aliran sesat lagi menyesatkan dan sudah keluar dari Islam karena Ahmadiyah menganggap ada nabi setelah Nabi Muhammad SAW yaitu Mirza Gulam Ahmad (Pendiri Ahmadiyah), inilah perbedaan prinsip yang tidak dapat ditoleransi. 
Untuk mencegah terjadinya perpecahan dalam sebuah bangsa perlu adanya kebijakan yang bermuara pada perubahan cara pandang daan cara merawat kehidupan kebangsaan secara cermat melalui sebuah wawasan tentang kebangsaan. Peranan pemimpin pemerintahan dalam penyelenggaraan negara melalui pemerintahan memegang peranan penting, hal tersebut ditunjukan dengan menjadi negarawan yang selalu mengambil kebijakan untuk warganegara bukan didasarkan pada kepentingan kelompok dan golongan.

\section{Konsep Starting Condition}

Konsep starting condition merupakan tahapan awal berupa mengidentifikasi problematika dan kekuatan antar-stakeholder yang akan berkolaborasi dalam aktualisasi kebijakan wawasan kebangsaan dalam penanganan konflik social sebagai salah satu gejala lemahnya wawasan kebangsaan yang menjadi perekat bangsa Indonesia. Politik-birokrasi sebagai salah satu factor yang memberikan dampak terhadap ikatan kebangsaan yang bersifat subyektif yang tergambarkan dalam bentuk structural yang menjadi pertimbangan rasional dalam bentuk kebijakan-kebijakan dan tindakan pemerintahan dalam mengelolah ekonomi, politik-pemerintahan, hukum dan militer sehingga lebih bersifat instrumental.

Pentingnya starting condition dalam kebijakan wawasan kebangsaan, karena lemahnya sikap ideologi masyarakat yang berdekatan dengan pusat peerintahan bila dibandingkan dengan masyarakat perbatasan yang memiliki sikap ideologi lebih kuat, bahkan masyarakat pulau jawa memiliki kadar ideologi yang rendah apabila dibandingkan dengan masyarakat di luar pulau Jawa (Muttaqin, dkk., 2006). Secara langsung hal terbut juga dialami oleh Kabupaten Pandeglang yang menjadai salah-satu Kabupaten yang dekat dengan pusat pemerintahan dan berada pada wilayah pulau Jawa.

Forum Koordinasi Pempinan Daerah (FORKOPIMNDA) menjadi dasar pemetaan kondisi awal dalam menjalankan kebijakan wawasan kebangsaan sebagai bagian dari Urusan Pemerintahan Umum lingkup daerah. kondisi awal pelaksanaan kebijakan wawasan kebangsaan melalui Forkopimda diharapkan menunjang terwujudnya stabilitas ketentanraman masyarakat dari tingkat prvinsi hingga tingkat kecamatan. Harapaan trsebut juga sejalan dengan langkah-langka FORKOPIMDA Kabupaten Pandeglang yang selalu melaksanakan koordinasi dan identifikasi kondisi stabiltas kehidupan masyarakat. Disamping itu juga Forkopimda juga menjadi wadah untuk menyelaraskan program kegiatan dalam menunjang berlangsungnya kehidupan berbangsa dalam kerangka Wawasan Kebangsaan . FORKOPIMDA menjadi sarana kolaborasi pemerintahan dalam mensinergitas pengambilan keputusan melalui proses dialog antarpimpinan instansi, sehingga dapat menjalin komitmen 
yang kuat dan meminimalisasi bias pemahaman antar-stakeholder dalam penyelenggaraan Urusan Pemerintahan umum dan mencegah terjadinya konflik sosial ditengah masyarakat. sejalan dengan peranan FORKOPIMDA tersebut

Peranan FORKOPIMDA dalam membantu mensinergikan semua kepentingan untuk menciptakan keseimbangan lingkungan kolaborasi, dan juga sebagai sarana meredam ketidakseimbangan latar belakang yang dimiliki oleh para pemangku kepentingan sangat signifikan. FORKOPIMDA juga menjadi sarana untuk merencaanakan kegiatan melalui proses dialog bersama untuk menghasilkan keuntungan dan menghindari ketidakpercayaan antar-stakholder yang berkolaborasi.

Keputusan Bupati Pandeglang Nomor 420/Kep. 107-Huk/2018 tentang Pembentukan Pengurus Pusat Pendidikan Wawasan Kebangsaan Kabupaten Pandeglang Periode 20182021, keputusan tersebut menghubungkan pemerintah dengan berbagai komponen pelaksana dari FORKOPIMDA untuk melaksanakan teknis kebijakan wawasan kebangsaan. Pelaksanaan kebijakan Wawasan Kebangsaan melalui proses kolaborasi akan sangat membantu menyelesaikan ketidakseimbangan latar belakang. Melalui Keputusan Bupati Pandeglang tersebut di atas, maka kelompok kepentingan disatukan dan dibangun infrastruktur organisasi yang kuat dan terarah dalam pelaksanaan kebijakan Wawasan Kebangsaan di Kabupaten Pandeglang. Melalui keputusan tersebut semakin banyak pihak yang terlibat, maka semakin banyak pihak yang memperoleh dampak dari kebijakan wawasan kebangsaan dan konflik sosial akan semakin mudah dapat diatasi karena adanya kesamaan di depan hukum serta penghormatan terhadap martabat sesama warganegara.

\section{Facilitative Leadership/Kepemimpinan Fasilitatif}

Kepemimpinan dalam konteks partisipatif dan kolaboratif sangat terkait erat dengan kepemimpinan deliberative dalam menyelesaikan masalah-masalah yang dihadapi bersama. Ufel mengatakan bahwa: "ability of the one or few who are at the top to make others do a number of things that they would not or at least might not have done" (Uefel, 2014). Pendapat tersebut menjelaskan bahwa kepemimpinan dapat dimaknai secara tunggal dalam arti seseorang atau juga daapat dipahami sebagai beberapa orang untuk membuat orang lain untuk menjalankan beberapa hal yang mungkin atau tidak mungki dilaksanakan. Secara konseptual pandangan kepemimpinan sejalan dengan makna kolaborasi kebijakan wawasan kebangsaan yang dilaksanakan di Kabupaten Pandeglang yang menyatukan pemangku kepentingan dalam pusat pendidikan wawasan kebangsaan untuk melaksanakan perannya masing-masing. 
Kepemimpinan dalam proses kolaborasi sangat dibutuhkan sebagai kendali atas komitmen yang telah dibentuk dalam menjalankan sinergitas latar belakang yang brbeda untuk tujuan yang sama. Secara luar kepemimpinan dipandang sebagai unsur penting dalam membawa pihak lain dalam kesepakatan bersama, kepemimpinan sebagai hal terpenting dalam proses negosiasi-negosiasi bersama pemangku kepentingan, selain itu kepemimpinan yang fasilitatif memiliki peran penting untuk menyatukan para kepentingan untuk saling terlibat dalam semangat kolaboratif.

Proses tata kelolah kolaborasi juga dibangun oleh pihak kepolisian sebagai tanggungjawab yang diemban dalam Forum Koordinasi Pimpinan Daerah yang tetap berkoordinasi dengan Bupati sebagai pemimpin dan ketua FORKOMPINDA. Secara formil tata kelolah kolaborasi dalam penanganan konflik social di tingkat Kabupaten Pandeglang telah dibentuk melalui Keputusan Bupati Nomor: 460/Kep.340-Huk/2016 yang diketuai oleh Bupati.

Proses kolaborasi di bawah pimpinan Bupati unit kepolisian melaksanakan kebijakan yang terkait dengan wawasan kebangsaan melalui program identifikasi persuasif terhadap masyarakat, hal tersebut harus dilakukan oleh Bupati sebagai pemimpin daghlam melaksanakan Intervensi, sesuai dengan pandangan Ansell and Gash bahwa: to move collaboration forward, leaders must often intervene in a more directive way to shape the agenda. Pandangan Ansell and Gash tersebut memposisikan pemimpin dalam proses kolaborasi sangat sentral dalam memberikan intervensi agar mengarahkan intervensi dengan cara yang lebih terarah untuk menjalankan agenda kebijakan wawasan kebangsaan (Ansell \& Gash, 2008).

Dalam mengatasi terjadinya konflik yang lebih banyak lagi di Kabupatn Pandeglang, Bupati Membentuk Tim Terpadu Pencegahan Konflik Sosial (TTPKS) yang terdiri dari kepolisian, kejaksaan, hingga Badan Pertanahan Nasional. Tim tersebut dipimpin Oleh Bupati dalam mengendalikan Konflik di Kabupaten Pandeglang. Langkah tersebut menunjukan kepemimpinan Bupati untuk tetap mempertahankan aturan dasar yang jelas melalui proses tata kelolah kolaborasi. Mengingat dalam kolaborasi sangat penting membangun kepercayaan, memfasilitasi dialog dan melakukan eksplorasi untuk terwujudnya tujuan bersama.

Kepemimpinan menjadi sarana pembelajaran dalam tata kelolah kolaborasi yang dapat diperoleh oleh para pemangku kepentingan. Kepemimpinan kolaborasi dutunjukan juga melalui sikap melayani proses (melakukan transformasi dan memfasilitasi) serta menjaga proses kolaborasi agar tetap berjalan stabil dalam menjaga keamanan dan kenyamanan 
masyarakat. Kepemimpinan juga ditunjukan dalam keberpihakan sharing anggaran dalam menjalankan peran masing-masing pemangku kepentingan, namun kenyataan dalam penanggulangan konflik belum adanya anggaran yang diperuntukkan untuk tindakan pencegahan konflik yang dilaksanakan oleh pihak kepolisian.

Menurut Ansell and Gash (2008), pemimpin kolaborasi harus memiliki 4 ketrampilan antara lain: "that collaborative leaders must have the skills to (1) promote broad and active participation, (2) ensure broadbased influence and control, (3) facilitate productive group dynamics, and (4) extend the scope of the process". Dalam pelaksanaan Kolaborasi kebijakan Wawasan kebangsaan patut diakui bahwa peranan kepemimpinan lebih banyak secara teknis dijalankan oleh Baadan Kesbangpol sebagai instansi teknis yang memiliki kewenangan menjalankan urusan wawasan kebangsaan di Kabupaten Pandeglang.

Mengingat wawasan kebangsaan sebagai sebuah nilai dalam kehidupan berbangsa, maka pentingnya pemimpin yang memberikan contoh merupakan simbol kualitas kepemimpinan yang merupakan kontekstual yang tepat dalam menanamkan nilai wawasan kebangsaan bagi semua kalangan dan pihak yang berkolaborasi. Secara factual terkadang penanaman nilai tidak sering juga mengalami bentrokan nilai di tengah masyarakat, hal tersebut juga disebabkan oleh telah tertanam lebih dulu nilai-nilai lain pada masyarakat maupun para pemangku kepentingan. Kondisi demikan sangat membutuhkan pemimpin yang responsive untuk menurunkan tingkat ketegangan yang muncul baik antarpemangku kepentingan maupun antar pihak yang berkolaborasi dengan masyarakat.

Kondisi tersebut terkadang juga memunculkan adanya nilai baru yang menjadi kesepakatan baru dalam menyelesaikan benturan yang terjadi. Nilai tersebut menjadi nilai baru yang menjadi dasar dalam membangun hubungan tata kelolah kolaborasi. Namun nilai tersebut bukanlah nilai substansi yang kolaborasi, karena nilai yang menjadi substansi dalam kolaborasi tetaplah nilai wawasan kebangsaan sebagaimana yang telah menjadi tujuan bersama. Munculnya nilai baru tersebut bukan tidak mungkin, muncul juga pihak-pihak baru yang menjadi mediator baru.

Hal yang menjadi tantangan tersendiri dalam pelaksanaan kolaborasi terkait dengan wawasan kebangsaan, intensitas Bupati sebagai pemimpin Kepala daerah memiliki keseriusan dalam melakukan control dan evaluasi kebijakan wawasan kebangsaan. Komunikasi yang intens antara Bupati, Kapolres dan Dandim untuk saling bertukar informasi dan sumber daya dalam menjaga keseimbangan interaksi masyarakat kabupaten Pandeglang. Proses pelaksanaan komunikasi secara intens dilakukan oleh Badan Kesbangpol dengan melibatkan lebih banyak stakeholder. Peranan pemimpin dalam proses kolaboasi yang 
berorientasi pada masa depan tujuannya adalam membangun dasar-dasar yang fundamental dari proses kolaborasi, sehingga proses kolaborasi menjadi berkelanjutan.

Mengingat masa depan bangsa sangat ditentukan pada pembinaan nilai wawasan kebangsaan bagi generasi muda melalui proses pendidikan. Kerangka model penanaman nilai-nilai kebangsaan tersebut sangat perlu menjadi perhatian pemerintah daerah melalui program dan kegiatannya. Proses pendidikan yang menjadi fokus kolaborasi tersebut perlu dipimpin oleh seseorang yang memiliki visi jangka panjang. Proses penanaman nilai wawasan kebangsaan dalam proses kolaborasi kebijakan pendidikan wawasan kebangsaan mendorong para pemangku kepentingan untuk melakukan fungsinya masing-masing sebagaimana pembagian yang telah ditetapkan.

\section{KESIMPULAN}

Implementasi kebijakan wawasan kebangsaan belum dilaksanakan secara tata kelolah kolaborasi, sehingga penanganan konflik sosial di Kabupaten Pandeglang masih belum terlaksana secara baik. Dominasi pemerintah dalam proses implementasi kebijakan wawasan kebangsaan masih sangat dominan serta desain kelembaannya belum secara penuh melibatkan peran serta aktor yang berkepentingan. Implementasi Kebijakan wawasan kebangsaan agar dapat dilaksanakan secara kolaboratif sangat perlu memperhatikan Aktor atau pihak yang berkepentingan untuk terlibat secara aktif dalam proses implementasi kebijakan dan perlu memperhatikan juga beberapa inti pelaksanaan kebijakan untuk menjadi pendukung pelaksanaan aktifitas yang berkaitan aktor yang terlibat.

Permasalahan wawasan kebangsan perlu dipahami sebagai permasalahan bersama yang menjadi tanggung jawab setiap individu warga negara, sehingga dalam pelaksanaannya perlu memperhatikan semua aspek baik sosial, ekonomi, politik, dan keraifan lokal dan budaya. Proses implementasi kebijakan wawasan kebangsaan merupakan aktualisasi dari rasa sadar akan kecintaan dan kebanggaan sebagai bagian dari bangsa indonesia yang diapresiasikan setiap warga negara, sehingga diperlukan kesetaraan untuk terlibat secara bersama-sama dalam implementasi kebijakan.

\section{DAFTAR PUSTAKA}

Ansell, C., \& Gash, A. (2008). Collaborative governance in theory and practice. Journal of public administration research and theory, 18(4), 543-571.

Foulcher, K. (2000). Sumpah Pemuda: The making and meaning of a symbol of Indonesian nationhood. Asian Studies Review, 24(3), 377-410. 
http://infopublik.id/read/57474/efektifitas-implementasi-kebijakan-pendidikan-wasbang-didaerah-.html, diakses tanggal 14 September 2019.

Kansil, C. S., \& Kansil, C. S. (2011). Empat Pilar Berbangsa dan Bernegara. Jakarta: Rineka Cipta.

Khasan, E. (2010). Memadukan Metode Kuantitaf dan Kualitatif. Bandung: Indra Prahasta.

Muttaqin, T., dkk. (2006). Membangun Nasionalisme Baru; Bingkai Ikatan Kebangsaan Indonesia Kontemporer. Jakarta: Kementerian Negara Perencanaan Penmbangunan Nasional/Bappenas.

Naisbit, J. (1994). Global Paradox: The Bigger the World Economy, the More Power full Its Smallest Players. New York: William Morrow.

Nasional, K. M. N. P. P. (2005). Rancangan Awal Rencana Pembangunan Jangka Panjang Nasional Tahun 2005-2025. Jakarta: Badan Perencanaan Pembangunan Nasional.

Nugroho, R. (2018). Kebijakan Membangun Karakter Bangsa. Jakarta: Elex Media Komputindo.

Poespowardojo, S. (1989). Filsafat Pancasila: sebuah pendekatan sosio-budaya. Bandung: Gramedia Pustaka Utama.

Stroomberg, J. (2018). Hindia Belanda 1930. IRCiSoD.

Sugiyono, D. (2010). Metode penelitian kuantitatif dan R\&D. Bandung: Alfabeta.

Uefel, W. (2014). Political Leadership in Deliberative Democracy. Lap Lambert Acadecc Publishing: Germany.

Wasistiono, S. (2015). Perkembangan Konsep Negara Bangsa (Nation State) dalam Era Globalisasi (Tinjauan dari Sudut Pemerintahan). Bahan Diskusi Kemenkopolhukkam tanggal 7 Oktober 2015. 